\title{
Os primórdios da relação entre literatura para a infância e ambiente em Portugal ${ }^{1}$
}

\author{
Angela Balça ${ }^{2}$ \\ Fernando Azevedo ${ }^{3}$
}

Resumo: Neste artigo procuramos fazer uma breve história dos primórdios da relação entre literatura para a infância e ambiente, em Portugal. As preocupações ambientais ganharam ênfase, a nível mundial, nos anos 70 do século XX e essas inquietações refletiram-se também nas obras de literatura para a infância. É nosso objetivo, neste texto, analisar o contexto social de produção destas obras, compreender que obras são estas, conhecer quais as obras mais emblemáticas do início desta relação entre literatura para a infância e o ambiente. No artigo, destacaremos os autores Sidónio Muralha e Ilse Losa.

Palavras-chave: Literatura para a infância; ambiente; Portugal

\section{The beginning of the relationship between children's literature and environment in Portugal}

Abstract: In this article, we give a brief history of the relationship between children's literature and environment in Portugal. Environmental concerns have gained emphasis, worldwide, in the 70 s of XX century and these concerns also reflected themselves in the works of children's literature. It is our goal, in this text, analyse the social context of the production of these works, understand what these works are, know which are the most emblematic works of the beginning of the relationship between children's literature and the environment. In this article, we will emphasize the writers Sidónio Muralha and Ilse Losa.

Key-words: Children's literature; environment; Portugal

\begin{abstract}
${ }^{1}$ Este trabalho foi financiado por Fundos Nacionais através da FCT (Fundação para a Ciência e a Tecnologia) e cofinanciado pelo Fundo Europeu de Desenvolvimento Regional (FEDER) através do COMPETE 2020 - Programa Operacional Competitividade e Internacionalização (POCI) no âmbito doCIEC (Centro de Investigação em Estudos da Criança da Universidade do Minho) com a referência POCl-01-0145-FEDER-007562.

${ }^{2}$ Professora Auxiliar do Departamento de Pedagogia e Educação da Universidade de Évora (Portugal).Membrodo Centro de Investigação em Estudos da Criança (CIEC) - Universidade do Minho(Portugal). Doutora em Ciências da Educação pela Universidade de Évora.E-mail: apb@uevora.pt

${ }^{3}$ Professor Associado com Agregação do Instituto de Educação da Universidade do Minho (Portugal).Membrodo Centro de Investigação em Estudos da Criança (CIEC) - Universidade do Minho.Doutor em Ciências da Literatura pela Universidadedo Minho. E-mail: fraga@ie.uminho.pt
\end{abstract}

\begin{tabular}{|l|l|l|l|l|} 
Textura & Canoas & v. 19 n.39 & p. 19-34 & jan./abr. 2017 \\
\hline
\end{tabular}




\section{LITERATURA PARA A INFÂNCIA E AMBIENTE: UMA RELAÇÃO PROFÍCUA}

Neste artigo procuramos abordar o início da relação entre a literatura para a infância e a construção de uma sociedade onde sustentabilidade é a palavra de ordem. Em Portugal, desde os anos 70 do século XX que os textos de literatura para a infância se debruçam e refletem sobre as mais variadas preocupações relacionadas com o problema do ambiente e com a criação de uma sociedade mais sustentável. Dessa forma, neste texto, são nossos objetivos compreender como se iniciou e qual o contexto social que possibilitou esta conexão entre a literatura para a infância e as problemáticas ambientais, que obras são simbólicas no dealbar desta relação e quais são os escritores mais emblemáticos.

Os temas ligados ao ambiente nem sempre tiveram, a nível mundial, o mesmo tratamento e nem sempre foram objeto das mesmas inquietações. Um dos marcos mais importantes para a discussão dos problemas ambientais foi a Conferência das Nações Unidas sobre o Meio Ambiente Humano, realizada em Estocolmo, na Suécia, no ano de 1972. Esta Conferência permitiu, na época, inserir as questões ambientais entre as prioridades dos governos; chamou a atenção do mundo para os problemas do crescimento da população a nível global, para a poluição atmosférica e para a exploração violenta dos recursos naturais; e possibilitou a consciencialização das populações para todas estas problemáticas.

Nesta Conferência foi produzido um importante documento, com um carácter político-jurídico, que ficou conhecido como a Declaração da Conferência das Nações Unidas sobre o Meio Ambiente Humano (1972). Neste documento, reconhecia-se que o Homem tinha direito a viver num ambiente de qualidade, sendo esta particularidade aquilo que conferia dignidade à existência humana (Cf. https://pt.wikipedia.org/wiki/Confer\%C3\%AAncia_de_Estocolmo).

$\mathrm{Na}$ verdade, esta Conferência e a sua respetiva Declaração foram o início de um movimento em redor das questões ambientais, a nível mundial, que permanece até à atualidade e se materializa, em última instância, num conjunto de conferências e de cimeiras internacionais sobre estas temáticas. A mais recente, no ano de 2015, realizou-se na cidade de Paris, em França, mais uma vez patrocinada pelas Nações Unidas, tendo como tema fulcral a discussão sobre as alterações climáticas. 
O modo como estes temas relacionados com o ambiente foram encarados foi-se também modificando, ao longo das últimas décadas. Se a princípio tínhamos uma perspetiva mais de alerta, de denúncia, a esta juntou-se uma vertente que aponta para a construção de um equilíbrio sistémico entre o crescimento económico, o desenvolvimento social e cultural e a proteção e sustentabilidade do planeta. Se o ponto de vista antropocêntrico da humanidade privilegiou, desde sempre, a cultura sobre a natureza (BRADFORD, MALLAN, STEPHENS E MCCALLUM, 2008), hoje, com a crescente interconexão entre o local e o global, favorecedora de uma maior consciencialização cívica acerca das questões ambientais e acerca da necessidade do desenvolvimento sustentado do planeta (PISANI, 2001; GARRARD, 2004; BUELL, 2005), o ecocriticismo e a ecopedagogia (GAARD, 2009) parecem ter entrado na ordem do dia.

É nesta linha de pensamento que encontramos a temática da educação para a sustentabilidade, ao longo do currículo, no ensino oficial em Portugal, com uma ênfase particular nas disciplinas da área das Ciências. Assim, este currículo promove o conceito To live better on Earth (FOLQUE E OLIVEIRA, 2016), que "implies the sustainability of the whole Earth system" (FOLQUE E OLIVEIRA, 2016, s/p). De acordo com o currículo da Educação Básica português, o conceito

\begin{abstract}
To live better on Earth emphasizes human responsibility in upholding the balance of the Earth system and proposes strategies based on Science, Technology, Society, Environment Education (STSE Education). This formulation shows, moreover, the complex relationships between natural and social components of the environment and their interaction with individual and community health, in its broadest sense. (FOLQUE \& OLIVEIRA, 2016,s/p).
\end{abstract}

Deste modo, Folque e Oliveira (2016) chamam a atenção para as mais valias deste conceito, que coloca a tónica na responsabilidade do Homem para fomentar o equilíbrio no planeta, propondo estratégias que se baseiem na Ciência, na Tecnologia, na Sociedade, na Educação Ambiental, numa complexa teia de relações entre o natural e o social, entre o individual e o comunitário.

A literatura para a infância, nomeadamente em Portugal, não ficou imune a este movimento em redor do ambiente. Nas décadas anteriores aos anos 70, a natureza já era assídua nos textos literários para as crianças, como afirma 
Barreto (2002), mas sem se ter a consciência das graves e enormes dificuldades que atravessava o planeta Terra,

\begin{abstract}
Ao longo da história da literatura infantil portuguesa o ambiente (melhor, a Natureza) esteve quase sempre presente, das formas mais variadas. Histórias com bichos não têm conta. Histórias que falam de lugares, terras, povoações, povos, habitats, costumes, tradições, lendas, rios, mares, oceanos, florestas, são tantas que quase arriscaríamos dizer que não há livro infantil que, de algum modo, não aborde ou tenha por cenário elementos da Natureza. Quase sempre, também, para levar ao pequeno leitor uma ideia feliz, encantatória, do mundo que o rodeia. Em particular quando ninguém parecia ainda suspeitar que o Ambiente pudesse vir a precisar de atenções especiais, com vista a preservá-lo de práticas insensatas, destruidoras. (BARRETO, 2006, p. 36)
\end{abstract}

Assim, estas problemáticas ambientais só surgem claramente nas obras de literatura para a infância, publicadas nos anos 70 do século XX, potenciadas por acontecimentos políticos no país, como a Revolução de 25 de Abril de 1974, que possibilitou o derrubar da Ditadura e o instaurar da Democracia bem como a consequente abolição da censura. Aliás, o tema das questões ambientais é um dos que apresenta uma grande vitalidade e uma maior longevidade na literatura para a infância portuguesa, nas últimas quatro décadas.

A literatura para a infância sempre aliou, quanto a nós, várias vertentes. Por um lado, estes textos, porque são literários, apresentam uma perspetiva estética e lúdica; por outro lado, a esta perspetiva aliam uma vertente que pode ser claramente formativa. E de um modo geral, as obras de literatura para a infância, onde o ambiente marca presença, oferecem aos leitores mais jovens uma forte visão educativa e mesmo pedagógica.

$\mathrm{Na}$ verdade, autores há que consideram que o contacto da criança com narrativas literárias sobre a natureza (e sobre o ambiente de uma forma mais geral, acrescentamos nós), pode fomentar o seu desenvolvimento ecológicomoral, que a levará, certamente, a olhar o ambiente pelo seu valor intrínseco e numa perspetiva descentrada do ser humano (PIRES, 2007). Assim, podemos aproveitar a leitura destas obras, para uma mudança de atitude em relação à natureza, onde comportamentos de proteção e respeito em relação ao sistema ambiental possam auxiliar-nos a atingir o tão desejado e desejável desenvolvimento sustentável. 


\section{PRÉMIOS DE LITERATURA PARA A INFÂNCIA E AMBIENTE}

Uma das formas encontradas na sociedade portuguesa, para a promoção das questões ambientais junto dos mais novos, foi a escrita de obras literárias de potencial receção infantil que reflectissem sobre estas problemáticas. Acreditamos que este movimento foi também potenciado pelo surgimento, durante pelo menos três décadas, de prémios literários que galardoavam obras de literatura para a infância que abordavam a temática do ambiente. Nas próximas linhas, debruçar-nos-emos sobre esses prémios, que ainda hoje ecoam na comunidade literária e escolar portuguesa.

Ainda em pleno período revolucionário, decorrente da Revolução de 25 de Abril de 1974, surge o Prémio O Ambiente na Literatura Infantil. Importantíssimo pela sua longevidade (foi promovido entre os anos de 1976 e 1991), pela consolidação e surgimento de novos autores e pela capacidade de ainda hoje ser citado e relembrado, este Prémio era concedido, anualmente, pela Secretaria de Estado do Ambiente.

O Prémio tinha como objetivo principal “(...)contribuir para a divulgação, entre a juventude, de conceitos essenciais a uma educação preocupada com o ambiente e a conservação da Natureza." (PORTUGAL, 1985, p. 1864), centrando-se nos jovens, uma vez que "Sem embargo de o tema «Ambiente» ser já em si um relevante motivo, importa ainda tomar em atenção os destinatários da obra e realçar que as ações destinadas às camadas mais jovens de um povo tendem a frutificar exponencialmente." (PORTUGAL, 1985, p. 1864).Desta forma, pretendia-se promover uma educação ambiental, entre os mais novos, neste caso através de obras de literatura para a infância.

É ainda de referir que, em Nota ao Regulamento deste Prémio, publicado em Anexo ao Boletim da Comissão Nacional do Ambiente, de Dezembro de 1976, se adiantava que esta mesma Comissão iria sugerir ao Ministério da Educação que aconselhasse a obra premiada e outras obras que fossem de qualidade como textos escolares, pelo que desde o seu início este Prémio demonstrava grandes preocupações formativas.

Apesar da dinâmica do Prémio, só em 1985 é que foi publicada, em Diário da República, a primeira portaria (Portaria n. ${ }^{\circ} 426 / 85$, de 5 de Julho), que regulamentava e dava um enquadramento legal a este galardão. Esta Portaria regulamentava ainda o novo formato do Prémio, que já estava de alguma forma previsto desde 1978 (SOBRINHO, 1995), visto que nesse ano se 
alterou o regulamento do galardão, permitindo que pudessem apresentar-se a concurso obras inéditas conjuntamente com obras já editadas. Existiam assim duas modalidades para as obras a concurso, sendo a modalidade A para obras inéditas e a modalidade $\mathrm{B}$ para obras cuja primeira edição era relativa ao ano a que o Prémio se referia, mas só em 1987 é que se premiou uma obra na modalidade A.

O Prémio podia ser concedido a obras de prosa ou de poesia, escritas em língua portuguesa, independentemente da nacionalidade do seu autor. As obras deveriam evidenciar o significado das relações entre os seres vivos e a natureza, realçando o papel do Homem e deveriam veicular informações, referentes ao território nacional, que fossem corretas do ponto de vista científico e educacional.

A constituição do júri do Prémio revelava também a dupla preocupação, subjacente a este Prémio, uma vez que ele era composto pelo presidente da Liga para a Proteção da Natureza, por dois especialistas em ambiente e por dois escritores de literatura para a infância. Certamente com o intuito de reforçar a importância do tema e do Prémio, a entrega do mesmo fazia-se, se possível, no dia 5 de Junho, data que assinala o Dia Mundial do Ambiente (segundo Sobrinho (1995), desde 1981 que há referência a esta data como sendo a data da entrega do Prémio, uma vez que anteriormente a 1981 o mesmo era entregue no dia 2 de Abril, Dia Mundial do Livro Infantil).

A regulamentação e o enquadramento legal deste Prémio eram definidos ainda por duas outras portarias, posteriores à referida anteriormente. A Portaria n. ${ }^{\circ} 7 / 90$ de 8 de Janeiro previa que o regulamento do Prémio fosse atualizado e aprovado anualmente por despacho do Secretário de Estado do Ambiente e dos Recursos Naturais; a Portaria n. ${ }^{\circ}$ 57/92 de 30 de Janeiro adjudicava a organização do concurso para a atribuição do Prémio ao Instituto Nacional do Ambiente (INam), sendo o regulamento do concurso elaborado pelo mesmo instituto e aprovado anualmente pelo governo.

Segundo Sobrinho (1995), reconhecia-se assim o trabalho efetuado, desde a publicação da Lei n. ${ }^{\circ}$ 11/87, de 7 de Abril (Lei de Bases do Ambiente), pelo Instituto Nacional do Ambiente, na organização deste galardão. Estas duas últimas portarias mantiveram sempre o formato do Prémio, que previa as duas modalidades (A e B) para as obras a concurso.

O Prémio Adolfo Simões Muller não apresenta o relevo do galardão anterior, mas é revelador desta dinâmica relação entre literatura para a infância 
e ambiente. Este Prémio foi atribuído pela Editorial Verbo, entre 1991 e 1993, e constituía uma homenagem ao escritor homónimo, considerado um dos nomes maiores da literatura para a infância portuguesa. $\mathrm{O}$ regulamento deste Prémio, que se destinava a obras originais de escritores portugueses, referia que a intriga das mesmas deveria dirigir-se a crianças com a idade a partir dos 8 anos; que a ação da obra deveria decorrer em Portugal e as principais personagens deveriam ser portuguesas; e que, no concurso, dar-se-ia preferência às obras que, pelo tipo de personagens ou de construção da intriga, permitissem a sua continuação numa série de volumes independentes.

O júri deste Prémio era constituído por três escritores e por um representante da Editorial Verbo, que teria um voto de desempate. Este júri podia ainda indicar obras de qualidade, para além das premiadas, às quais a Editorial Verbo atribuiria uma menção honrosa. A Editorial Verbo comprometia-se a publicar a obra que fosse premiada.

A edição deste Prémio, no ano de 1993, teve um tema aglutinador, ao qual as obras a concurso tinham de se sujeitar - a ecologia. Assim, a intriga da obra deveria ser encaminhada no sentido de mostrar e alertar as crianças leitoras, para o problema da urgência da defesa e proteção do ambiente.

Numa reflexão mais aturada sobre estes dois Prémios, podemos afirmar que as preocupações com o ambiente eram uma constante na sociedade e o seu eco fazia-se sentir igualmente nas obras de literatura para a infância e na comunidade/sector literários em Portugal. Este facto é também revelado no envolvimento nestas problemáticas ambientais das esferas quer públicas quer privadas. Na verdade, estes Prémios foram patrocinados quer pelo sector público quer pelo sector privado. Mas mais do que isso, queremos enfatizar a relação estabelecida entre estas duas esferas, nem sempre conseguida e muitas vezes dependente da orientação política dos governos. E esta relação consubstanciou-se, por exemplo, entre a Editorial Verbo e o Estado, através do PrémioO Ambiente na Literatura Infantil. Esta casa editorial criou a coleçãoTerra Verde, que se iniciou com escritores premiados com o Prémio mencionado, coleção esta que tinha grandes preocupações formativas e ambientais, afirmando-se na contracapa das obras que Sensibilizar a criança na defesa do património natural não é obra meramente pedagógica, dando a entender que não só a escola, mas também a literatura para a infância tinha esta tarefa de formar as crianças, de promover uma verdadeira educação ambiental. 


\section{ALGUMAS OBRAS EMBLEMÁTICAS NA RELAÇÃO LITERATURA PARA A INFÂNCIA E AMBIENTE, NOS ANOS 70 DO SÉCULO XX}

Nesta parte do artigo, pretendemos dar conta de algumas obras que consideramos emblemáticas nesta caminhada inicial (e que hoje tem mais de quatro décadas) entre a literatura para a infância e o ambiente.

Alguns são então os autores que, nesses já longínquos anos 70, publicaram textos de literatura para a infância versando a temática ambiental. Dentre eles, destacaremos Sidónio Muralha e Ilse Losa, pelaqualidade,dimensão, atualidade,longevidade e persistência da sua obra.

Sidónio Muralha (Lisboa, 1920 - Curitiba, 1982), poeta e escritor português, que viveu longos anos no Brasil, editou, em 1976, a obra Valéria e a Vida, com a chancela da Livros Horizonte, na sua coleção Pássaro Livre. Com ilustrações de Soares Rocha, objeto de várias reedições, esta obra foi galardoada com o Prémio O Ambiente na Literatura Infantil. A obra Valéria e a Vida está também editada no Brasil, pela Fundação Sidónio Muralha, sediada em Curitiba. Atualmente, esta obra faz parte das listas do Plano Nacional de Leitura, numa versão vinda a lume já no século XXI, pela mão da Editora Gailivro e com ilustrações de Inês Oliveira.

Valéria e a Vida é uma obra cuja mensagem principal se centra na denúncia das questões da poluição. Recorrendo à personificação, uma figura de retórica muito comum e muito querida dos leitores mais novos, a protagonista Valéria faz um passeio pela natureza ouvindo as queixas dos vários personagens $-\mathrm{o}$ riacho, os peixes, as plantas e as árvores, a chuva, o mar, o ar, o solo, os animais. Com uma estrutura paralelística, onde se recorre e relembra informação anterior, facilitando a leitura das crianças, esta narrativa alerta para o encadeamento entre todos os elementos da natureza, que obviamente se reflete também em relação à poluição.

Esta narrativa encerra igualmente uma estrutura gradativa, em crescendo, começando por apresentar os problemas que afetam o ambiente mas, a partir de certa altura, aduzindo uma solução, que seria protagonizada pelas crianças.

$\mathrm{Na}$ obra, o grande poluidor do planeta é o Homem "Os homens não sabem o que fazem - disse mais uma vez Valéria. - É preciso que todas as crianças do mundo, que serão os homens do futuro, salvem a Natureza." (MURALHA, 1976, p.17). E, na verdade, a texto explora esta dicotomia entre 
os homens, neste caso entendidos como os adultos, e as crianças. Se os homens são considerados os grandes poluidores, não sabem o que fazem, são ignorantes, são mentirosos e não têm juízo, assume-se as crianças, aqui simbolizadas pela personagem principal, Valéria, como as salvadoras do planeta. Na narrativa, as crianças são as únicas dignas de confiança, porque não mentem, tal como a natureza, porque a sua palavra não está poluída, porque

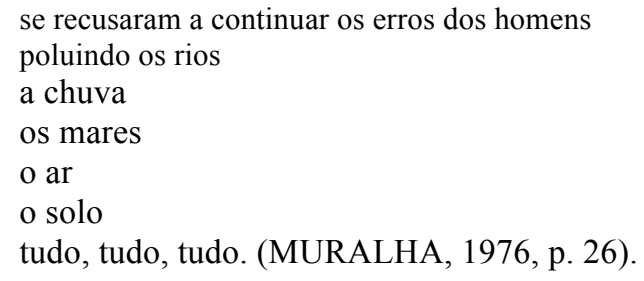

Apresentando uma enorme carga poética, portadora de uma mensagem clara e feroz, suportada num design gráfico apelativo e inovador, esta edição de 1976 da obra Valéria e a Vida constitui-se como uma verdadeira obra de literatura para a infância, capaz de potenciar o desenvolvimento ecológicomoral da criança, dado que lhes reserva um papel primordial e fundamental na defesa e proteção intransigentes do planeta Terra.

Ilse Losa (Alemanha, 1913 - Porto, 2006) foi uma premiada escritora portuguesa, de origem judaica, que publicou, em 1976, a obra Beatriz e o Plátano, com ilustrações de Luísa Couwenbergh, na coleção Asa Juvenil, das Edições Asa. Esta obra foi objeto de várias reedições e integra, na atualidade, as listas do Plano Nacional de Leitura.

A obra Beatriz e o Plátano (LOSA, 1976) ilustra, perante as crianças, o que cada um de nós pode fazer para lutar ativamente em defesa do planeta e do meio ambiente, constituindo uma forma de assegurar a promoção de uma consciência ecocrítica e de fomentar o desenvolvimento ecológico-moral dos mais novos. Confrontada com a iminência do derrube do velho e enorme Plátano, situado diante do antigo edifício dos Correios, que dera nome à rua, a pequena Beatriz, depois de procurar, de forma infrutífera, a ajuda dos adultos, decidiu escrever uma carta às autoridades - "Ao saber que o Plátano ia ser cortado pelas autoridades foi logo mandar uma carta a essas autoridades, mas ninguém ligou a essa carta." (LOSA, 1976, s/p). 
Não tendo obtido resposta à sua carta, Beatriz insistiu com uma ação de desobediência civil, facto que garantiu a preservação e o salvamento da velha árvore -

"Beatriz ficou a dormir debaixo do Plátano porque os senhores podiam ir cortar o Plátano durante a noite. Como os pais sabiam que a Beatriz não ia desistir levaram uns cobertores e alimentos." (LOSA, 1976, s/p).

Se esta é uma ação inicialmente individual e, no final, co lectivamente aplaudida, protagonizada por uma criança, ela mostra aos jovens leitores que nunca se deve desistir dos princípios e dos valores em que se acredita, mesmo que, por vezes, as forças dominantes se encontrem alheadas deste esforço. Em Beatriz e o Plátano (LOSA, 1976), o recurso a um caso concreto permite não apenas interrogar determinadas práticas sociais, como também defender ativamente uma reorientação ética (ZAPF, 2008), à luz da qual a defesa de uma árvore é assumida como forma de olhar e de preservar o Outro.

Marcadas pela denúncia de problemas que afetavam e atingem, ainda hoje, o planeta Terra, Valéria e a Vida centra-se sobretudo nas questões da poluição e Beatriz e o Plátano alerta para a proteção das árvores e para o seu papel nos centros urbanos. Parece-nos, contudo, que o estilo de Sidónio Muralha e de Ilse Losa serão diferentes, na aproximação destes temas às crianças.

Se Ilse Losa mostra um estilo mais contido, consubstanciado também no design mais clássico da obra, já Sidónio Muralha apresenta uma escrita que, embora poética, consideramos mais panfletária, mais audaz, onde se evidenciam frases muito diretas, destacadas no corpo do texto, que certamente têm impacto a quando da leitura da obra pelas crianças,

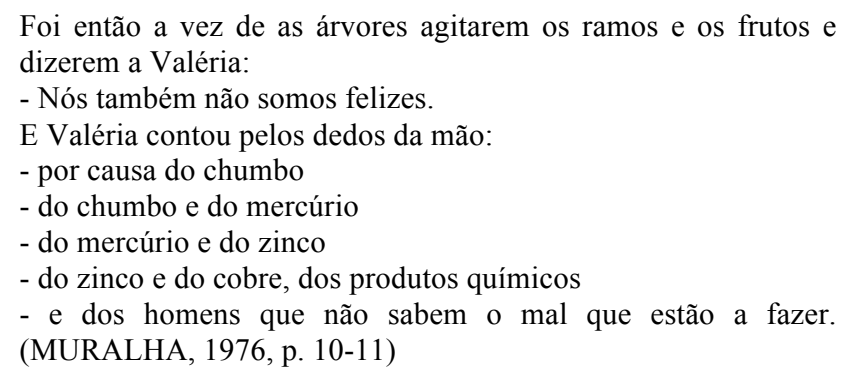


O design gráfico da obra Valéria e a Vida é, na verdade, como já referimos anteriormente, muito inovador para a época, mostrando uma perfeita distribuição das ilustrações e do texto, ao longo das páginas, não obedecendo ao tradicional alinhamento de uma página para o texto e uma página para a ilustração. As ilustrações, embora destinadas às crianças, quer pelas cores fortes utilizadas (o preto, o cinzento, o castanho escuro, o verde e o vermelho) quer pela representação da natureza e dos fatores que a ameaçam, são um aliado muito eficaz na transmissão da mensagem desta obra. A mesma coisa já não poderemos afirmar das ilustrações, para o mesmo texto, de Inês Oliveira, para a reedição da Editora Gailivro, que pelos tons mais claros e mais pastel e pelo próprio traço e representação da natureza se apresentam de uma candura que, quanto a nós, não acompanham a força e o arrojo desta narrativa literária Sidónio Muralha.

$\mathrm{Na}$ verdade, as obras de Sidónio Muralha e de Ilse Losa mencionadas são, a nosso ver, simbólicas, no cenário literário português, da relação estabelecida entre a literatura para a infância e o ambiente. Vários fatores contribuem para esta circunstância. Estas duas obras foram editadas em 1976, ainda no rescaldo da Revolução de 25 de Abril de 1974 e da abertura na sociedade portuguesa aos mais variados e inovadores temas, mesmo na literatura para a infância.Parece-nos, igualmente, que estas obras se inserem e vêm na linha das preocupações levantadas, em 1972, na Conferência das Nações Unidas sobre o Meio Ambiente Humano. A atualidade destas narrativas literárias bem como a qualidade da sua escrita contribuiu, certamente, para as sucessivas reedições e para a sua entrada no Plano Nacional de Leitura, fazendo com que as crianças do século XXI continuem a lê-las e a poder pensar e debater, através delas, sobre as questões da sustentabilidade do planeta Terra, nas suas múltiplas vertentes.

Não queremos terminar este olhar, sobre textos de literatura para a infância dos anos 70 do século XX, sem referir ainda outras obras que tocaram a temática do ambiente.

Novamente da autoria de Sidónio Muralha, a obra Voa, pássaro, voa é uma coletânea de poemas para crianças, editada pela Livros Horizonte, em 1978, e ilustrada por Fernando Lemos, em tons de azul e branco. Estas cores tornam a obra, quanto a nós, bastante simbólica, dado que podem remeter o leitor para a cor do planeta Terra, o chamado Planeta Azul, e para a esperança no seu futuro sustentável. Muito embora se nos afigure que a maioria dos poemas, apesar de se centrarem nos animais e na natureza, não encerram só 
por si preocupações ambientais, queremos destacar dois, onde estas problemáticas podem ser vislumbradas.

No poema As Grades, pressentimos a temática da liberdade, em geral, e da liberdade dos animais, em particular. O poema leva-nos para o universo dos pássaros presos em gaiolas, muito comum nas casas portuguesas. Porém, a nosso ver, e numa leitura mais profunda do poema, acreditamos que há aqui uma exortação e uma certeza na liberdade para todos os seres do planeta "Um pássaro entrou na gaiola vazia/e a gaiola fechou a alegria.(...)/Cheia de pássaro a gaiola/cantarola, cantarola,/mas o pássaro tem asas/e vai deixar a gaiola." (MURALHA, 1978, p. 31).

Temática e interpretação semelhante ocorre-nos para o poema Pássaro Livre. Desta vez a referência vai para a porta e a janela abertas que possibilitam o despertar do pássaro para a liberdade "A porta aberta./Aberta a janela./O pássaro desperta.(...)/Voa, pássaro, voa.” (MURALHA, 1978, p. 32). Ambos os poemas levam-nos, de facto, para os anos 70, em Portugal, e para o clima de abertura e de liberdade vivido após a Revolução de 25 de Abril de 1974. Todos os temas se tornam possíveis de ser abordados, todos os sonhos parecem alcançáveis num clima de liberdade, também simbolicamente representado pelos pássaros.

Outra obra que assinalamos é a coletânea de contos, de Sílvia Montarroyos, galardoada, em 1977, com o Prémio O Ambiente na Literatura Infantil, intitulada Histórias do bichinho qualquer ${ }^{4}$. Dentre os vários contos, destacamos, a título de exemplo, as narrativas Breve história de uma bola de sabão e História de um raio de sol.

Em Breve história de uma bola de sabão (Montarroyos, 1980), surge-nos a vida urbana, caracterizada pelos prédios de apartamentos minúsculos, pelos grandes centros comerciais, pelos empregos nas fábricas, pelas filas para os transportes públicos. Simultaneamente, encontramos nesta narrativa a poluição, provocada pelos fumos tóxicos das fábricas, pelos adubos químicos, pelos lixos, pelos resíduos. A protagonista deste conto é uma bola de sabão que, após acordar de um sono de alguns anos, constata como as fábricas poluem o ar, como os campos estão contaminados com os adubos químicos, como o mar está cheio de detritos, como as pessoas vivem nas cidades. A

4Dado que no mercado editorial não foi possível encontrar a $1 .^{a}$ edição desta obra, que data de 1977, para a escrita deste artigo socorremo-nos da 2. ${ }^{a}$ edição da mesma, com data de 1980. 
narrativa termina com um desenlace que tem uma dimensão simbólica, que convida a criança a refletir sobre as questões ambientais que afetam o planeta, fazendo mesmo o narrador um apelo às crianças leitoras, para que todas contribuam para que o nosso país não apresente este tipo de problemas,

E a bola de sabão viaja até hoje pelas ondas do mar, à espera de um dia ir parar a alguma terra onde a vida e não a morte more nas águas, no ar, na terra, e no coração de todos. Por que não fazermos com que a primeira dessas terras seja Portugal? (MONTARROYOS, 1980, p. 11)

Em História de um raio de sol (MONTARROYOS, 1980), um raio de sol, que passeia pela Terra, ensina a uma criança como aproveitar a energia solar, mostrando-lhe todas as suas vantagens, e apresentando os seus benefícios para a natureza, através de explicações de carácter pedagógico -

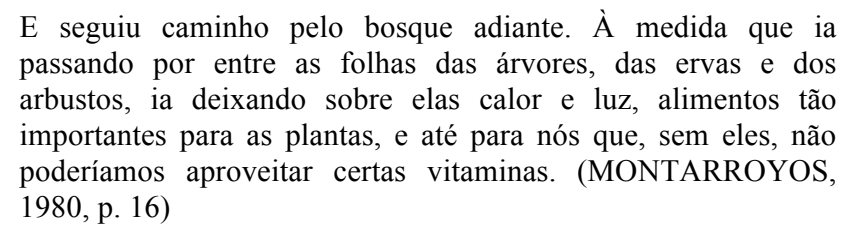
passando por entre as folhas das árvores, das ervas e dos arbustos, ia deixando sobre elas calor e luz, alimentos tão importantes para as plantas, e até para nós que, sem eles, não poderíamos aproveitar certas vitaminas. (MONTARROYOS, 1980, p. 16)

Este conto tem como tópico o aproveitamento de recursos naturais e almeja ensinar a usufruir, de forma equilibrada, dos recursos oferecidos pela natureza.

Seria possível, certamente, ainda convocar outros textos literários para a infância e outros autores para este artigo. Todavia, relembramos que, segundo Blockeel (2001), a evolução e a renovação na literatura para a infância portuguesa, registada após a Revolução de 25 de Abril de 1974, tardou ainda cerca de cinco anos. E esta circunstância pode ser, porventura, também comprovada pelo facto de nos anos de 1978 e 1979, não ter sido atribuído o Prémio $O$ Ambiente na Literatura Infantil, dado que, segundo os documentos da Comissão Nacional do Ambiente, o júri considerou que nenhuma das obras que se apresentou a concurso reunia condições para ser galardoada, formulando-se "um juízo extremamente crítico sobre a qualidade dos trabalhos apreciados" (SOBRINHO, 1995, p. 6) quer a nível científico quer a nível literário. 
Ainda de acordo com Blockeel (2001), os primeiros anos a seguir à Revolução foram tempos caóticos, que se refletiram também nas narrativas para crianças, as quais possuíam um valor literário reduzido, visto que as preocupações eram mais de teor ideológico. Assim, a maioria destas narrativas desapareceu do mercado editorial, atualmente.

Apesar destes factos, consideramos que foi nesta época, de certeza rica de discussão e emoção, que se iniciou uma frutífera relação entre a literatura para a infância e as questões do ambiente.

\section{CONSIDERAÇÕES FINAIS}

Neste artigo debruçámo-nos sobre os primórdios da relação entre a literatura para a infância e o ambiente. Muito embora a natureza tenha marcado presença nos textos literários, de um modo geral de uma forma idílica, nos anos 70 de século XX as problemáticas do ambiente e a ameaça ao planeta Terra fazem a sua entrada na literatura para a infância.

Em Portugal, acreditamos que este facto se deve a dois acontecimentos marcantes na década de 70: a nível mundial, a realização, em 1972, da Conferência das Nações Unidas sobre o Meio Ambiente Humano; em 1974, a Revolução de 25 de Abril de 1974, que instaurou a Democracia portuguesa e promoveu a abolição da censura.

Uma maior tomada de consciência dos problemas ambientais que afetavam o planeta e o incentivo à escrita de obras literárias para crianças, através de vários prémios que conjugavam literatura e ambiente, deram origem a um conjunto de obras que apresentaram grande vitalidade e longevidade.

Em relação aos anos 70 do século $\mathrm{XX}$, destacámos dois escritores emblemáticos - Sidónio Muralha e Ilse Losa - lançando o nosso olhar mais detalhado sobre duas obras simbólicas para esta temática do ambiente Valéria e a Vida e Beatriz e o Plátano.

Ao terminarmos, referimos que a temática do ambiente continua viva no atual panorama literário para crianças em Portugal, com textos de denúncia, de alerta, mas igualmente de esperança num mundo mais sustentável. 


\section{REFERÊNCIAS}

BARReto, Garcia. Dicionário de Literatura Infantil Portuguesa. Porto: Campo das Letras, 2002.

BLOCKEEL, Francesca. Literatura juvenil portuguesa contemporânea: identidade e alteridade. Lisboa: Caminho, 2001.

BRADFORD, Clare; MALLAN, Kerry; STEPHENS, John; MCCALLUM, Robyn. New world orders in contemporany children's literature. Utopian transformations.New York: Palgrave Macmillan, 2008.

BUELL, Lawrence. The future of environmental criticism: environmental crisis and literary imagination. Malden, MA, and Oxford: Wiley-Blackwell, 2005 .

FOLQUE, Maria Assunção; OLIVEIRA, Vítor. Early Childhood Education For Sustainable Development in Portugal. In: SIRAJ-BLATCHFORD, Jonh; PARK, Eunhye (Eds.) (Forthcoming) International Research on Education for Sustainable Development in Early Childhood, New York: Springer, 2016 (no prelo).

GAARD, Greta. Children's environmental literature: ecocriticism to ecopedagogy, Neohelicon, n. 36, p. 321-334, 2009.

GARRARD, Greg. Ecocriticism. The new critical idiom. London and New York: Routledge, 2004.

LOSA, Ilse. Beatriz e o Plátano. Porto: Edições Asa, 1976.

MONTARROYOS, Sílvia. Histórias do bichinho qualquer. 2." ed.Porto: Afrontamento, 1980.

MURALHA, Sidónio. Valéria e a Vida. Lisboa: Livros Horizonte, 1976. Voa, pássaro, voa. Lisboa: Livros Horizonte, 1978.

PIRES, Maria Natividade. Sociedade e natureza: que contribuições para uma identidade?. In: AZEVEDO, F. (Org.). Imaginário, identidades e margens. Estudos em torno da Literatura Infanto-Juvenil. V.N. Gaia: Gailivro, 2007. p. 162-173. 
PISANI, Edgard. Une certaine idée du monde. L'útopie comme méthode. Paris: Seuil, 2001.

PORTUGAL. Portaria 426/85, de 5 de Julho de 1985.Institui dois prémios designados «O Ambiente na Literatura Infantil». Diário da República, Lisboa, 5 jul. 1985. Disponível em: $<$ https://dre.pt/application/file/a/183106>. Acesso em: 29 set. 2016

SOBRINHO, José. Memórias de um prémio. Informar: revista do Instituto de Promoção Ambiental, n. 12, p. 6-8, 1995.

ZAPF, Hubert. Literary ecology and the etics of texts. New Literary History, n. 39, p. $847-868,2008$.

Recebido em 26/10/2016

Aprovado em 05/12/2016 